\title{
POWER SYSTEM DAMPING ENHANCEMENT VIA COORDINATED DESIGN OF PSS \& TCSC
}

\author{
A. Ahmed, O. Z. Amer, and \\ Electrical Engineering Department, Faculty of Engineering, Assiut \\ University, Assiut, Egypt
}

\section{Y. A. Mobarak}

Electrical Engineering Department, Faculty of Engineering, King

Abdul-Aziz University, Kingdom of Saudi Arabia

\section{(Received November 24, 2010 Accepted January 16, 2011)}

\begin{abstract}
The main objective of this paper is to investigate the enhancement of power system stability via coordinated design of Thyristor Controlled Series Compensation (TCSC) and Power System Stabilizers (PSSs) in multi-machine power system. The problems that are to be faced in the planning stage are appropriate type, location, size and setting of these controllers for various applications. In order to address this problem, an effort is made in this project to study technical issues of TCSC controller in type, capacity and placement, and other pertinent information relating to power system in developing nations.
\end{abstract}

KEYWORDS: FACTS, TCSC, PSS, Multi-Band, Delta-Pa, Delta-w, Multi-machine Power System.

\section{INTRODUCTION}

Modern electric power utilities are facing many challenges due to ever-increasing complexity in their operation and structure. In the recent past, one of the problems that got wide attention is the power system instabilities [1] - [3]. With the lack of new generation, transmission facilities and over exploitation of the existing facilities geared by increase in load demand make these types of problems are more imminent in modern power systems. In recent years, several major phenomena have been observed and reported in many countries such as France, Belgium, Sweden, Germany, Japan, the United States, etc [2]. These phenomena usually result in widespread blackouts. Information gathered and preliminary analysis, so far, from the most recent blackout incident in North America on 14th August 2003, are pointing the finger on voltage instability due to some unexpected contingency [4]. Even through it is premature to make it as a conclusive remark, the voltage instability could have had a major role in the incident as has been the case in the past in major blackout incidents. In this incident, reports indicate that approximately 50 million people interrupted from continuous supply for more than 15 hours [4]. Most of the incidents are believed to be related to heavily stressed system where large amounts of real and reactive power are transported over long transmission lines while appropriate real and reactive power resources are not available to maintain normal system conditions. Many electric utilities have made lot of efforts in system study in order to relieve the system from stability problem. 
Instability in power system could be relieved or at least minimized with the help of most recent developed devices called Flexible AC Transmission System (FACTS) controllers [3], [5]. The use of Flexible AC Transmission System (FACTS) controllers in power transmission system have led to many applications of these controllers not only to improve the stability of the existing power network resources but also provide operating flexibility to the power system. In addition, with relatively low investment compared to new transmission or generation facilities, these FACTS technology allows the industries to better utilize the existing transmission and generation reserves, while enhancing the power system performance. They clearly enhance power system performance and also provide an optimal utilization of the existing resources [6].

FACTS devices are a family of high-speed electronic devices, which can significantly increase the power system performance by delivering or absorbing real and/or reactive power [3], [5], [6]. There are many types of FACTS controllers available in real power system and some are under research. Static Var Compensator (SVC), Static Synchronous Compensator (STATCOM), Thyristor-Controlled Series Capacitor (TCSC), Static Synchronous Series Compensator (SSSC) and Unified Power Flow Controller (UPFC) are popular FACTS devices [6]. They can be connected to power system at any appropriate location, in series, in shunt or in a combination of series and shunt. The SVC and STATCOM are connected in shunt, whereas TCSC and SSSC are connected in series. UPFC has shunt and series circuit. Application of FACTS to enhance power system stability is an important issue. The problems that are to be faced in the planning stage are appropriate type, location, size and setting of these controllers for various applications.

\section{STUDIED SYSTEM AND MODELING}

The studied system (Kundur's Four-Machine Two-Area Test System) consists of two fully symmetrical areas linked together by two $230 \mathrm{kV}$ lines of $220 \mathrm{~km}$ length as shown in figure (1). The test system is specially designed to study low frequency electromechanical oscillations in large interconnected power systems [2,7]. Despite its small size, it mimics very closely the behavior of typical systems in actual operation [2]. Each area is equipped with two identical round rotor synchronous acts as thermal plant generators rated 20kV/900MVA connected to 20/230 KV transformers. The synchronous machines have identical parameter, except for inertias which are $\mathrm{H}=6.5 \mathrm{~s}$ in area $\# 1$ and $H=6.175 \mathrm{~s}$ in area \#2. The parameters of the generators, turbines and exciters data are given in [2].

Thermal generating plants having identical speed regulators are further assumed at all locations, in addition to fast static exciters with a gain on 200 [2]. Each generator produces $700 \mathrm{MW}$. The load is represented as constant impedances and split between the areas in such a way that area \#1 is exporting 413MW to area \#2. Since the surge impedance loading of a single line is about $140 \mathrm{MW}$ [1], the system is somewhat stressed, even in steady-state. The two-area power system is a simplest test system can be fixed any type of the known power system stabilizers on the four machine excitation system to provide better performance of the exciter control. Also, we can examine the effect of connected FACTS devices on the system response parameters when subjected to different types of disturbances. 


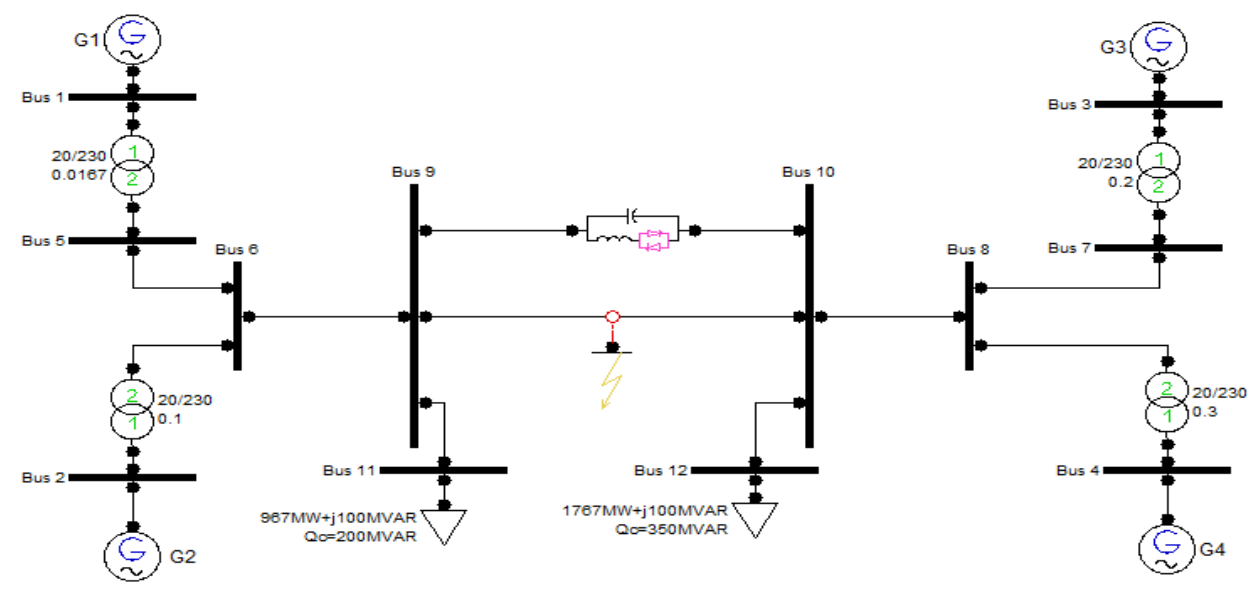

Figure (1) the single line diagram of the studied system

\section{OVERVIEW OF TCSC AND ITS CONTROL SYSTEM}

A TCSC controller is basically a TCR in parallel with a bank of capacitors. A typical single module TCSC structure for current control is shown in Figure (2). In a TCSC, two mains operational blocks can be clearly identified, i.e. an external control and an internal control [3]. The function of the external control is to operate the controller to fulfill specified compensation objectives; this $\square$ control $\square$ directly depends on measured systems variables to define the reference for the internal control, which is defined by the value of the controller reactance. The function of the internal control is to provide the right gate drive signals for the thyristor valve to produce the appropriate compensating reactance. Thus, the functional operation of the controller is defined by the external control $[3,8]$.

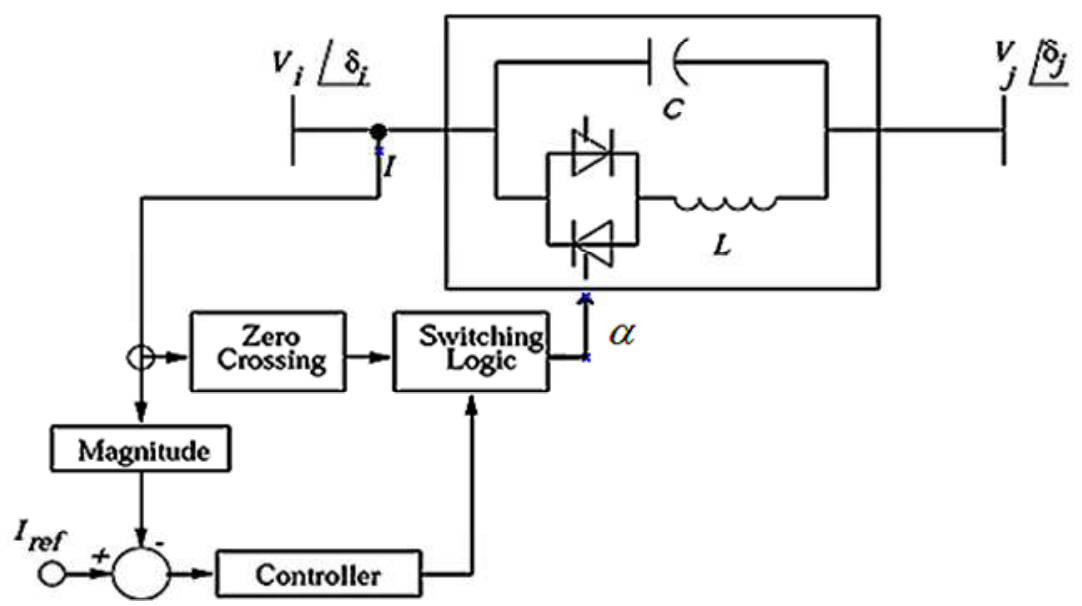

Figure (2): Basic TCSC structure with current control. 
The external control is defined by the control objectives. The typical steady state function of a TCSC is reactance control, but additional functions for stability improvement, such as damping controls, included in this control. The general block diagram of the TCSC model and external control structure used here is shown in Figure (3) [9].

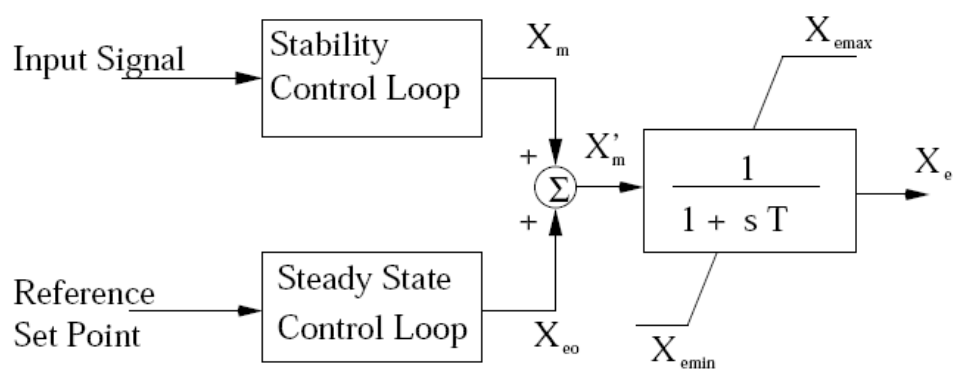

Figure (3): TCSC model for stability studies.

In this Figure, $X_{m}$ is defined by the stability control modulation reactance value which is determined by the stability or dynamic control loop, and $X_{\mathrm{eo}}$ stands for the TCSC steady state reactance or set point, whose value is provided by the steady state control loop. The sum of these two values results in $\mathrm{X}^{\prime}{ }_{\mathrm{m}}$, which is the net reactance order from the external control block. As the natural response of the device internal control is characterized by the delayed action, this signal is put through a firstorder lag that yields the equivalent capacitive reactance $X_{e}$ of the TCSC [10]. The steady state control loop may have a large time constant or be adjusted manually; hence, for large-disturbance transients, $X_{\mathrm{eo}}$ is assumed here to be constant. The equivalent reactance of TCSC is a function of the firing angle $\alpha$, based on the assumption of a sinusoidal steady-state controller current; hence, the operating limits are defined by the limits of firing angle $\alpha$. The range of the equivalent reactance is

$$
\mathrm{Xemin} \leq \mathrm{Xe} \leq \mathrm{Xemax} \text {, with Xemax }=\mathrm{Xe}(\alpha \min ) \text { and Xemin }=\mathrm{Xe}(\alpha=90)=\mathrm{Xc} \text {, }
$$

Where $\mathrm{Xc}$ is the reactance of TCSC capacitor.

The general structure of the stability controller is shown in Figure (4) [10]. It consists of a washout filter, a dynamic compensator, and a limiter. The washout filter is used to avoid a controller response to the dc offset of the input signal. The dynamic compensator consists of two (or more) lead-lag blocks to provide the necessary phaselead characteristics. Finally, the limiter is used to improve controller response to large deviations in the input signal.

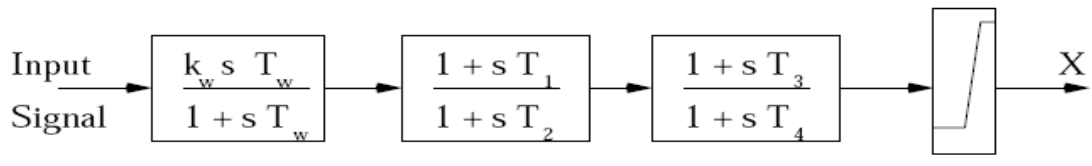

Figure (4) Block diagram of the TCSC stability control loop 


\section{POWER SYSTEM STABILIZERS (PSS)}

A PSS can be viewed as an additional block to a generator excitation control or Automatic Voltage Regulator (AVR), added to improve the overall power system dynamic performance, especially control electromechanical oscillations. This is a very effective method of enhancing small-signal stability performance on a power system network. PSS involves a transfer function consisting of an amplification block, a wash out block and two lead-lag blocks. The lead-lag blocks provide the appropriate phaselead characteristic to compensate the phase lag between the exciter input and the generator electrical torque. The proposed PSS input is one of the following signals:

\subsection{Acceleration Power based Power System Stabilizer (dPa-PSS):}

The output signal of the PSS is used as an additional input (Vstab) to the excitation system. The PSS input signal can be the acceleration power (difference between the mechanical power and the electrical power $(\mathrm{Pa}=\mathrm{Pm}-\mathrm{Pe}))$. The proposed (dPa-PSS) block model is shown in figure (6) [11]

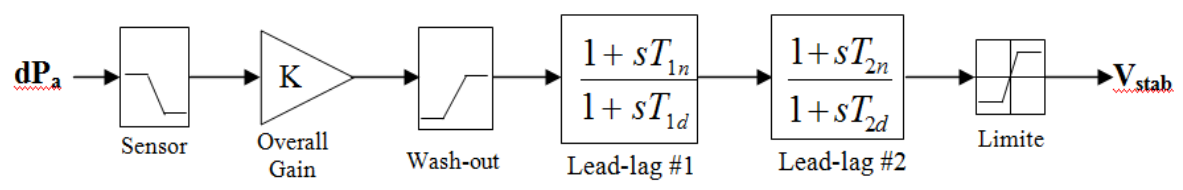

Figure (6) Accelerating Power based PSS (dPa-PSS) model

\subsection{Rotor Speed Deviation based Power System Stabilizer (dw- PSS):}

The d $\omega$-PSS provides an auxiliary signal control to excitation system (difference between synchronous speed and generator speed), the d $\omega$-PSS consists of Sensor Time Constant, Gain, Wash-out Filter, Lead-Lag Compensator, and a Limiter. The d $\omega$-PSS model is shown in Figure (7) [12].

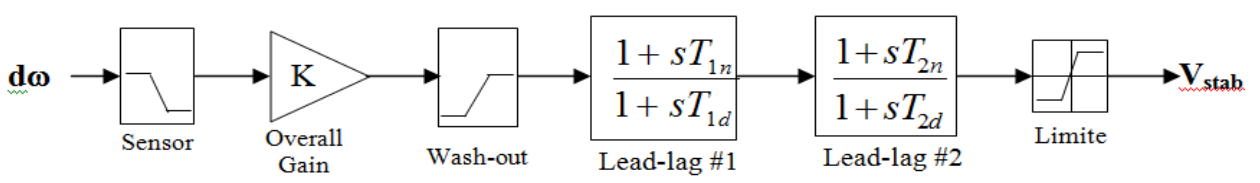

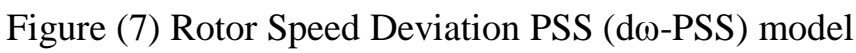

\subsection{Multi-Band Power System Stabilizer (MB-PSS):}

Multi-Band Power System Stabilizer (MB-PSS) is designed to damp all the disturbances occurring in an electrical power system with dw as an inject signal. The disturbance induces electromechanical oscillations to electrical generators on system. MB-PSS model is shown in Figure (8) [11, 12].For PSS data see appendix. 


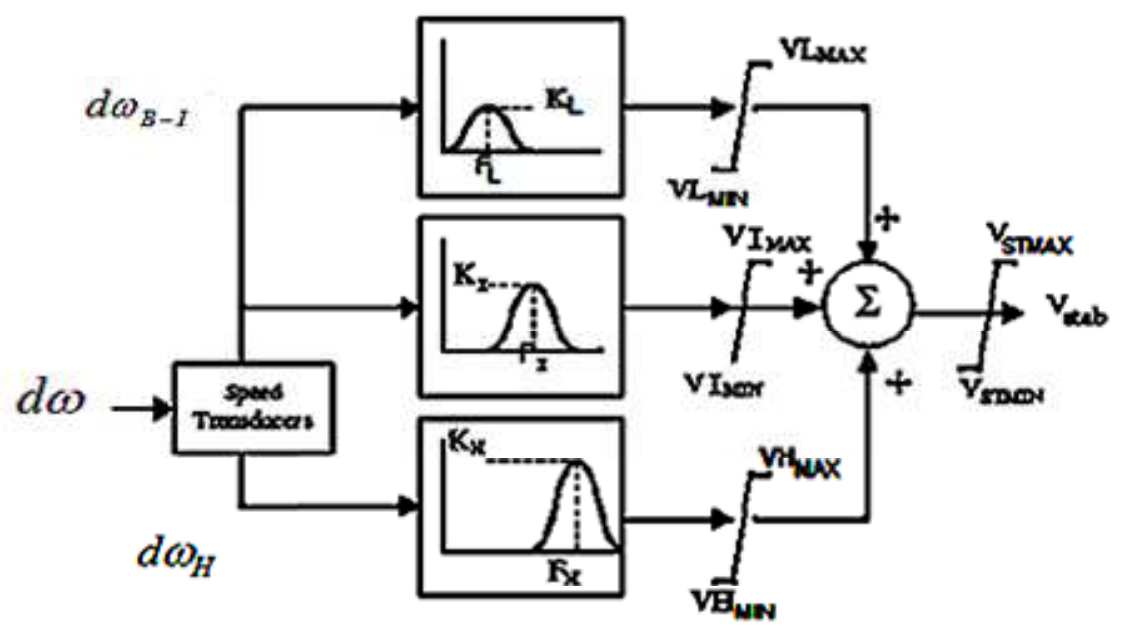

Figure (8) Multi-Band PSS (MB-PSS) model

\section{RESULTS AND DISCUSSIONS}

\section{5-1 System variables responses due to three phase disturbance:}

The test system was subjected to severe disturbance of three-phase fault occurred at the mid point of one tie-line and cleared after $(8$ cycles) $130 \mathrm{~ms}$. With applying dPa-PSS, $\mathrm{d} \omega$-PSS and MB-PSS to the excitation system, the following figures show the system parameters transient response during this fault disturbance. Comparison between the three types of PSS in terms of their effect on the system parameters responses is achieved by each one independently. It can be observed from the simulation results that, PSS provide sufficient damping to the system oscillations. The MB-PSS and d $\omega$ PSS are more effective than the dPa-PSS. d $\omega$-PSS shows better performances and superior responses over those obtained with MB-PSS and dPa-PSS especially with rotor angle and terminal voltage. Also, d $\omega$-PSS provides the best response with the speed deviation and excitation voltage. This means that the PSS can stabilize the system under various types of disturbances. Noting that with (TCSC) and d $\omega$-PSS over all disturbances, damped oscillations are recorded which have lead to stability after 3.0 seconds approximately from the disturbance application time. Most of the significant variables such as the angle delta, the machine speed deviation, the terminal voltage, and the tie-line power are plotted in Figure (9). 


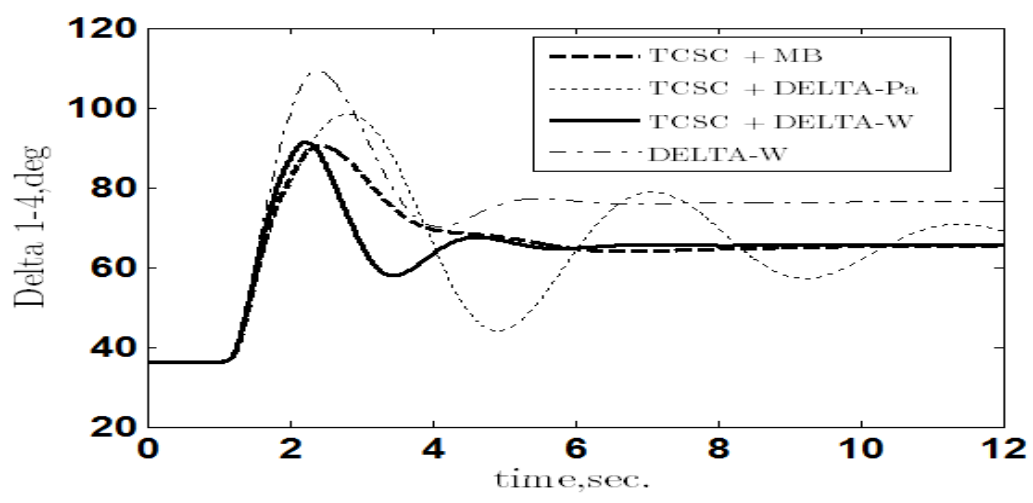

(a) Angle delta $\delta-14$ in (deg.)

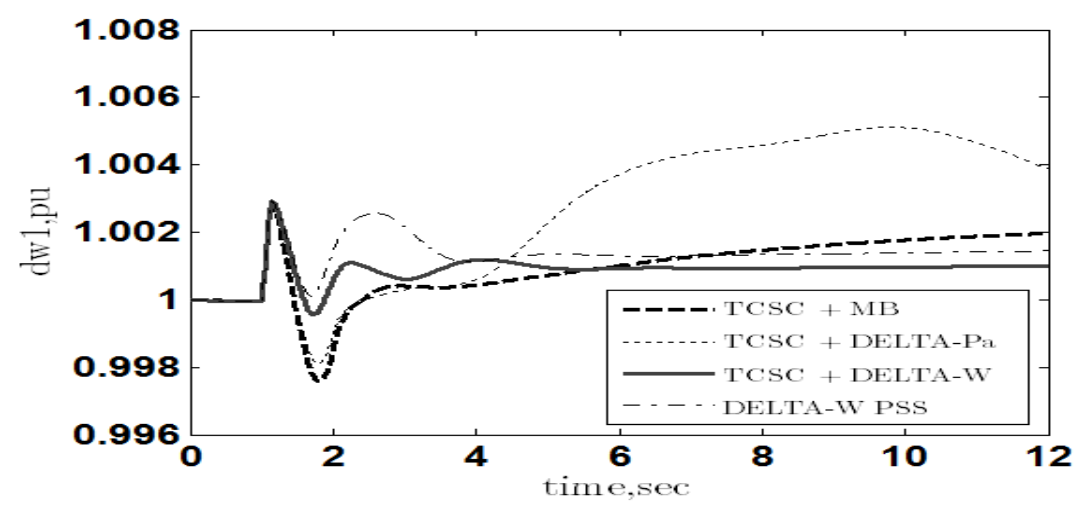

(b) Speed deviation $\mathrm{d} \omega-1$ in (p.u)

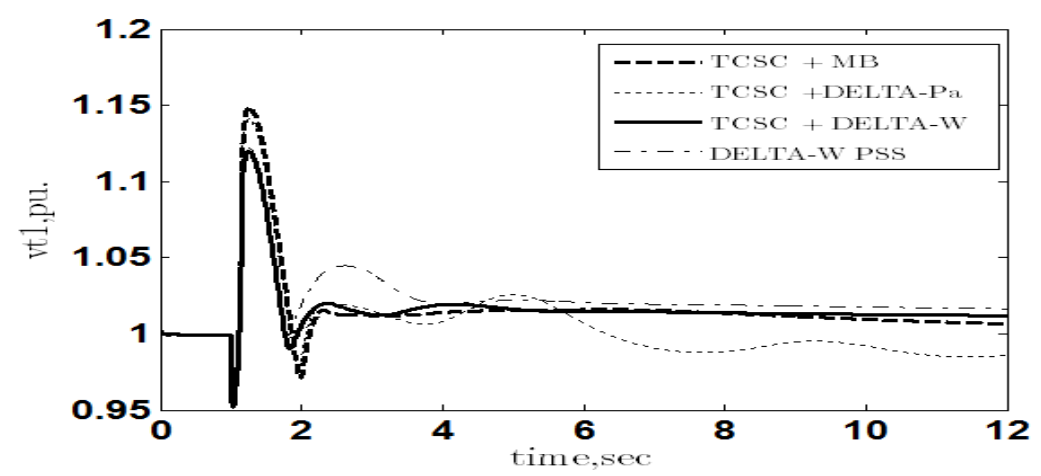

(c) Terminal voltage Vt-1 in (pu) 


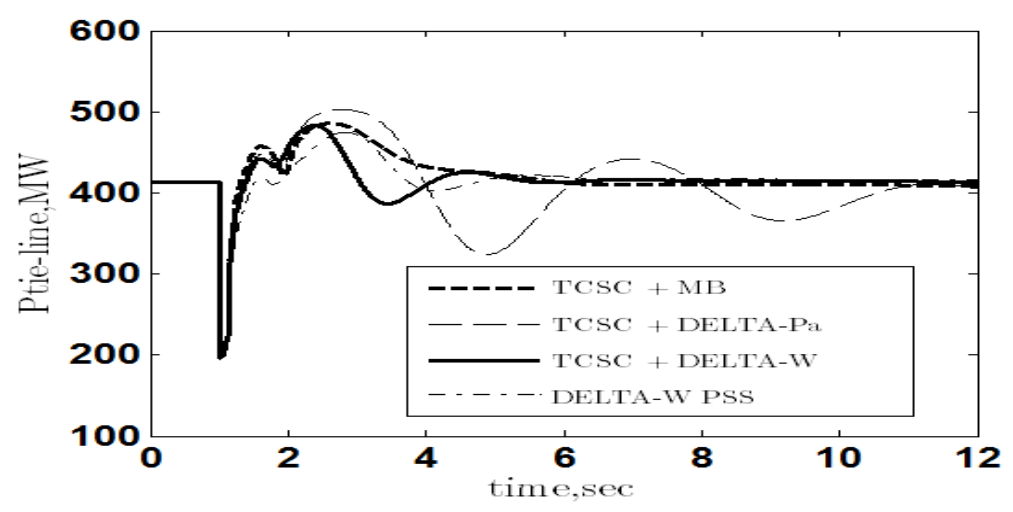

(d) Tie-line power Ptcsc 1-2 in (MW)

Figure (9) System responses after three-phase fault with line outage disturbance for $130 \mathrm{sec}$

\section{5-2 System variables responses after one line opening disturbance:}

If one of the two tie-lines is opened, it is possible to see effectiveness of TCSC to enhance power system stability. Noting that with (TCSC) and d $\omega$-PSS and at all disturbances damped oscillation is recorded which has lead to stability after 3.0 seconds from the disturbance application instant. Most of the significant variables such as the angle delta, the machine speed deviation, the terminal voltage, and the tie-line power are plotted in Figure (10).

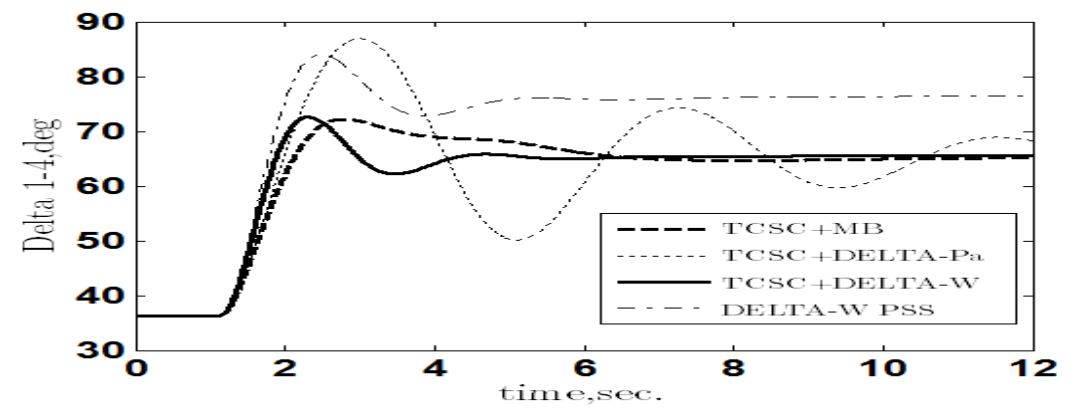

(a) Angle delta $\delta$-14 in (deg.)

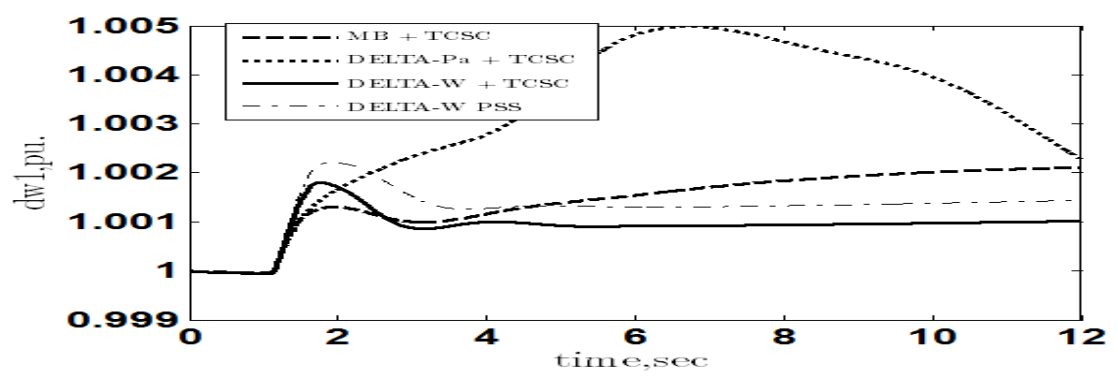

(b) Speed deviation $\mathrm{d} \omega-1$ in (p.u) 


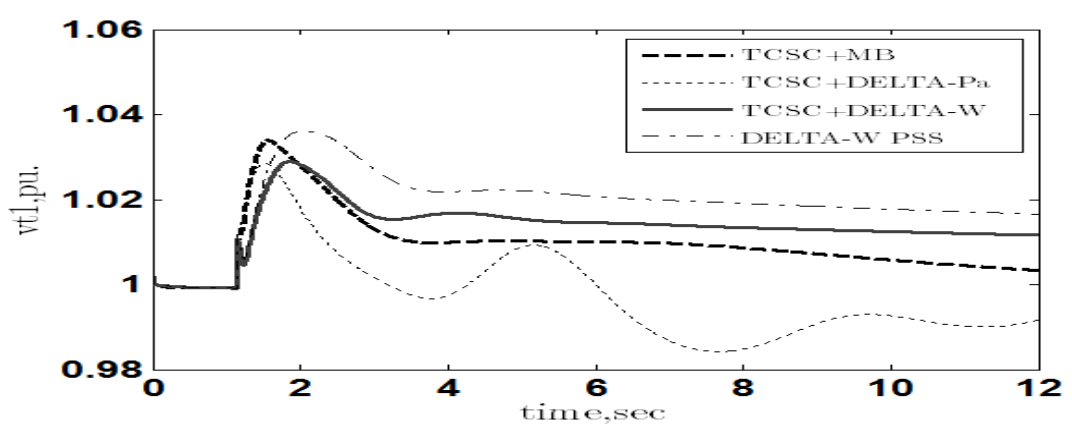

(c) Terminal voltage $\mathrm{V}_{\mathrm{t}^{-1}}$ in (pu)

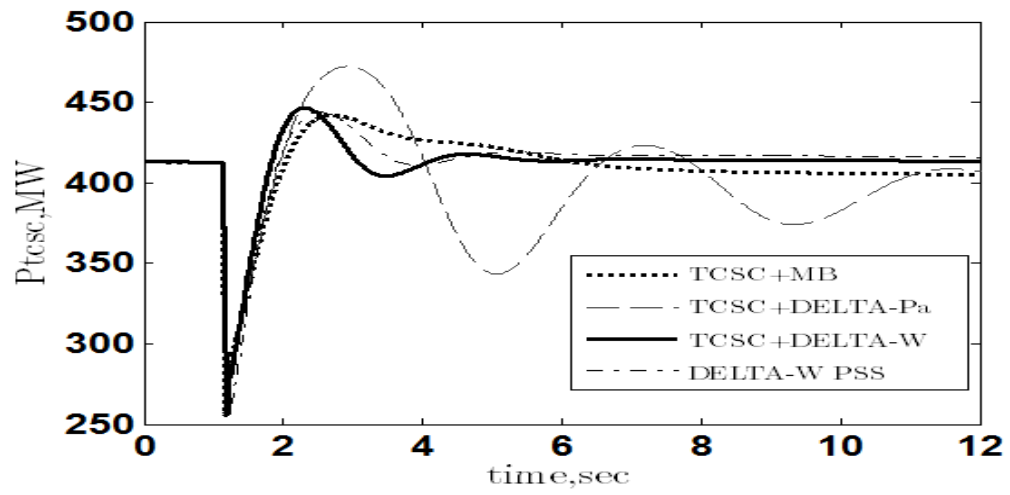

(d) Tie-line power $\mathrm{P}_{\text {tcsc }} 1-2$ in (MW)

Figure (10) System responses after one line opening disturbance

\section{CONCLUSIONS}

In this study a coordination design of TCSC and PSS stabilizers is proposed. The proposed stabilizer have been applied and tested on a weakly connected multimachine power system under sever disturbance. The time domain simulation results show the effectiveness of proposed stabilizer and its ability to provide good damping of low frequency oscillation and improve greatly the system voltage profile.

\section{REFERENCES}

[1] EPRI, Interconnected Power System Dynamics Tutorial, January 1998.

[2] Kundur, P., "Power System Stability and Control", McGraw-Hill, 1994.

[3] N. G. Hingorani, L. Gyugyi, "Understanding FACTS; Concepts and Technology of Flexible AC Transmission Systems," IEEE Press book, (2000).

[4] http://www.cnn.com/2003/US/08/14/power.outage/, October 2003

[5] Y. H. Song and A. T. Johns, Flexible AC Transmission System (FACTS), IEE Power and Energy Series 30, 1999.

[6] Cigre 95 TP108, FACTS Overview, IEEE Power Engineering Society, 1995.

[7] Mobarak Youssef, Naoto Yorino and Yoshifumi Zoka,“ A Simulink Multi-Band Power System Stabilizer (MB-PSS) and Static Var Compensator (SVC) 
Controls", Proc. of the Institute of Electrical Engineers of Japan, IEEJ'07, Nagoya, Japan, pp. 25-30, on July 31th -Agu. 2nd (2007).

[8] N. Martins, H. Pinto, and J. Paserba. "Using a TCSC for Power System Scheduling and System Oscillation Damping-Small Signal and Transient StabilityStudies". In Proc. IEEE/PES Winter Meeting, Singapore, January.

[9] A. D. Del Rosso, C. A. Ca nizares, and V. M. Do na, "A Study of TCSC Controller Design for Power System Stability Improvement," Accepted to IEEE Trans. on Power Systems, September 2002. Impact of Interactions Among System Controllers. CIGRE Task Force 38.02.16, November 1999.

[10] J. Paserba, N. Miller amd E. larsen, and R. Piwko, "A Thyristor Series Controlled Compensation Model for Power System Stability Analysis ," IEEE Trans. on Power Systems, vol. 10, no. 4, November 1995, pp. 1471-1478.

[11] Youssef. A. Mobarak, "A Simulink Multi-Band Power System Stabilizer", Journal of Engineering Sciences, Assiut University, Vol. 35, No. 2, pp. 489-507, March, 2007.

[12] M. Z. El-Sadek, G. Shabib, Y. A. Mobarak and M. H. El-Ahmar, "Combined Controls of STATCOM Device and Multi-Band Power System Stabilizer in Power System", Journal of Engineering Sciences, Assiut University, Vol. 37, No. 1, pp. 115-124, Jan., 2009.

\section{APPENDICES}

Appendix A: TCSC data:

$\mathrm{C}=2.28 \mathrm{e}-4 \mathrm{~F}, \mathrm{Xc}=11.6 \Omega, \mathrm{L}=0.00412 \mathrm{H}, \mathrm{Xl}=1.55 \Omega$, resonance point $\alpha=57^{0}$, Comp. $=10 \% . \mathrm{KP}=0.8, \mathrm{KI}=.08, \mathrm{~T} 1=0.05, \mathrm{~T} 2=0.016$.

Appendix B: PSS data:

1- $\mathrm{d} \omega$-PSS: $\quad \mathrm{K}=30$, Lead lag stage $1: \mathrm{T} 1=.05, \mathrm{~T} 2=.02$,

Lead lag stage 2 : $\mathrm{T} 1=3, \mathrm{~T} 2=5.4$.

2- MB-PSS: $\mathrm{K}=1, \mathrm{KL}=30, \mathrm{KH}=160$.

3- dPa-PSS: $\mathrm{K}=3.125$, Lead lag stage 1:T1=.060, $\mathrm{T} 2=1$,

Lead lag stage $2: \mathrm{T} 1=\mathrm{T} 2=0$.

\section{وحدات مكثقات التوالى المحكومة لاتزان نظم القوى}

يتتاول البحث دراسة تطبيق وحدات مكثفات التوالي المحكومة ومنظم القوى الكهربائية لاتزان نظم القوى للحصول

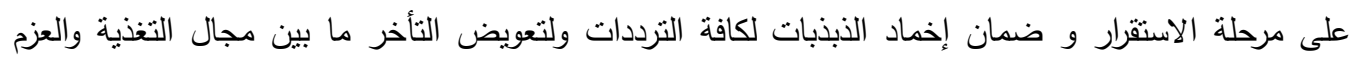

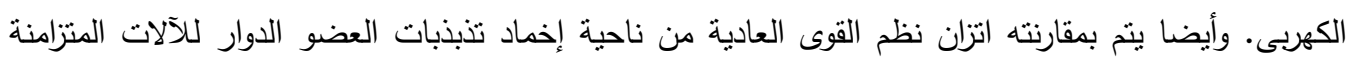
بواسطة التحكم في تغذيتها أثناء الاضطرابات الناتجة في نظم القوى. أداء وحدات مكثفات التوالي المحكومة المستخدمة في تحسين استقرار نظم القوى يكون فعال ومتطور لهحاكاة النظام العابر غير الخطى بعد عدة

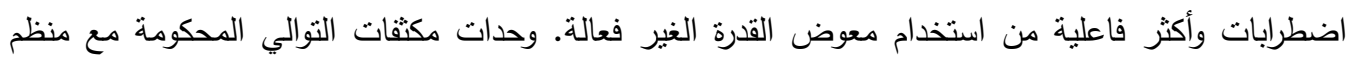
القوى الكهربائية أثثتت في هذه الدراسة سرعة إعادة استقرار الثبكة بعد الاضطرابات المختلفة. واثبت فعاليته عن

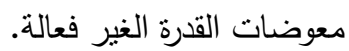

